\title{
Does intra-aortic balloon support for myocardial infarction with cardiogenic shock improve outcome?
}

\author{
Mohamed Y Khashan' and Michael R Pinsky*1,2 \\ University of Pittsburgh Department of Critical Care Medicine: Evidence-Based Medicine Journal Club, edited by Sachin Yende
}

\section{Expanded abstract Citation}

Thiele H, Zeymer U, Neumann FJ, Ferenc M, Olbrich HG, Hausleiter J, Richardt G, Hennersdorf M, Empen K, Fuernau G, Desch S, Eitel I, Hambrecht R, Fuhrmann J, Böhm M, Ebelt H, Schneider S, Schuler G, Werdan K; IABP-SHOCK II Trial Investigators: Intraaortic balloon support for myocardial infarction with cardiogenic shock. N Engl J Med 2012, 367:1287-1296.

\section{Background}

In the current international guidelines, intra-aortic balloon pump (IABP) counterpulsation is considered a class I treatment for acute myocardial infarction complicated by cardiogenic shock. However, evidence is based mainly on registry data, and there is a paucity of randomized clinical trials.

\section{Methods}

Objective: To test the hypothesis that IABP counterpulsation, as compared with the best available medical therapy alone, results in a reduction in mortality among patients with acute myocardial infarction complicated by cardiogenic shock for whom early revascularization is planned.

Design: Randomized, prospective, open-label, multicenter trial.

Setting: Thirty-seven centers in Germany.

Subjects: All adults had acute myocardial infarction complicated by cardiogenic shock and were expected to undergo early revascularization (by means of percutaneous coronary intervention or bypass surgery).

*Correspondence: pinskymr@ccm.upmc.edu

'Department of Critical Care Medicine, 606 Scaife Hall, 3550 Terrace Street,

University of Pittsburgh, Pittsburgh, PA 15261, USA

Full list of author information is available at the end of the article
Intervention: After enrollment, 600 patients were randomly assigned to intra-aortic balloon counterpulsation (IABP group, 301 patients) or no IABP counterpulsation (control group, 299 patients).

Outcomes: The primary efficacy endpoint is 30-day allcause mortality.

Results

At 30 days, 119 patients in the IABP group (39.7\%) and 123 patients in the control group (41.3\%) had died (relative risk with IABP, 0.96; 95\% confidence interval, 0.79 to $1.17 ; P=0.69$ ). There were no significant differences in secondary endpoints or in process-of-care measures, including the time to hemodynamic stabilization, the length of stay in the intensive care unit, serum lactate levels, the dose and duration of catecholamine therapy, and renal function.

\section{Conclusions}

The use of IABP counterpulsation did not significantly reduce 30 -day mortality in patients with acute myocardial infarction complicated by cardiogenic shock for whom an early revascularization strategy was planned.

\section{Trial registration \\ ClinicalTrials.gov number NCT00491036.}

\section{Commentary}

Cardiogenic shock complicates $7 \%$ to $10 \%$ of patients with acute myocardial infarction and carries a mortality rate approaching $70 \%$ to $80 \%$ [1]. Intra-aortic balloon pump (IABP) counterpulsation has been used routinely as an adjuvant treatment for myocardial infarction complicated by cardiogenic shock on the basis of evidence that it is associated with hemodynamic improvements [2]. Given the lack of randomized clinical trials, recommendations for adjunctive therapy in this high-risk population have been based only on pathophysiological assumptions and expert opinion. 
An IABP is a device placed in the descending thoracic aorta that inflates with diastole, increasing upstream coronary perfusion, and that deflates with systole, decreasing left ventricular (LV) afterload and, in turn, overall myocardial oxygen demand for a given cardiac output in the setting of cardiogenic shock. The use of IABPs as a bridge to support LV function originated in the 1960s, when coronary artery bypass surgery was just becoming available. Today, IABP counterpulsation is considered one of the most widely used mechanical assist devices in hemodynamically unstable cardiac patients.

The international guidelines endorsed the use of IABP in treating cardiogenic shock post-myocardial infarction with class 1 recommendation [3,4], despite the lack of adequately powered randomized trials and the recent metaanalysis data that show limited efficacy of IABP use [5].

The Intra-aortic Balloon Pump in Cardiogenic Shock II (IABP-SHOCK II) trial was a prospective multicenter randomized trial conducted at 37 German medical centers over a 3-year period. Six hundred patients with acute myocardial infarction complicated by cardiogenic shock were randomly assigned in a 1:1 ratio to either IABP or no IABP. There were no significant differences between the groups in terms of baseline characteristics or clinical course before random assignment. The major outcome was 30-day all-cause mortality. At 30 days, there was no significant difference in relative risk for death between the two groups (relative risk of death with IABP, 0.96; 95\% confidence interval, 0.79 to $1.17 ; P=0.69$ ). There were no significant differences in secondary endpoints and process-of-care outcomes (that is, lactate, C-reactive protein levels, renal function, and Simplified Acute Physiology Score II). Importantly, IABP was not associated with any significant increase in adverse events, including similar rates of reinfarction, stent thrombosis, bleeding, sepsis, or stroke. This multicenter randomized controlled study was well designed in the setting of cardiogenic shock with excellent recruitment of subjects based on eligibility.

However, general issues with this trial deserve consideration. The control and IABP groups had similar low mortality rates of $40 \%$ compared with previous registries and randomized clinical trials, which reported mortality rates of over $65 \%$. This suggests that the patients studied in this trial had less severe cardiovascular decompensation and may not represent the highest-risk patient cohort with severe cardiogenic shock. Second, there was crossover of $10 \%$ of the control group to IABP therapy and a more frequent use of left ventricular assist devices (LVADs) in control patients $(7.4 \%$ versus $3.7 \%)$, and both of these factors might decrease the control group mortality if IABP and LVAD use is beneficial. Third, the timing of IABP insertion was not controlled for. Fourth, the study reports only short-term results. Clearly, cardiac mortality is best assessed by 6 - and 12-month mortality rates, if not longer. For example, the SHOCK trial did not show survival differences at 30 days but did see a survival benefit at 6 months [6]. Those longer-term results from this trial are needed to confirm the neutral effect of IABP treatment.

\section{Recommendation}

In view of the lack of prior controlled clinical trials or other convincing evidence, this study challenges the current level I guideline recommendations for the use of IABP counterpulsation in patients with acute myocardial infarction complicated by cardiogenic shock. In this setting, the routinely used IABP counterpulsation need not be the default therapeutic approach.

Abbreviations

IABP, intra-aortic balloon pump; LV, left ventricular; LVAD, left ventricular assist device.

Competing interests

The authors declare that they have no competing interests.

\section{Author details}

'Department of Critical Care Medicine, 606 Scaife Hall, 3550 Terrace Street, University of Pittsburgh, Pittsburgh, PA 15261, USA. ${ }^{2}$ The Clinical Research, Investigation, and Systems Modeling of Acute IIIness (CRISMA) Center, 606 Scaife Hall, 3550 Terrace Street, University of Pittsburgh, Pittsburgh, PA 15261, USA.

\section{Published: 6 March 2013}

\section{References}

1. Goldberg RJ, Spencer FA, Gore JM, Lessard D, Yarzebski J: Thirty-year trends (1975 to 2005) in the magnitude of, management of, and hospital death rates associated with cardiogenic shock in patients with acute myocardial infarction: a population-based perspective. Circulation 2009, 119:1211-1219.

2. Ohman EM, George BS, White CJ, Kern MJ, Gurbel PA, Freedman RJ, Lundergan C, Hartmann JR, Talley JD, Frey MJ: Use of aortic counterpulsation to improve sustained coronary artery patency during acute myocardial infarction: results of a randomized trial. Circulation 1994, 90:792-799.

3. Antman EM, Anbe DT, Armstrong PW, Bates ER, Green LA, Hand M, Hochman JS, Krumholz HM, Kushner FG, Lamas GA, Mullany CJ, Ornato JP, Pearle DL, Sloan MA, Smith SC Jr., Alpert JS, Anderson JL, Faxon DP, Fuster V, Gibbons RJ, Gregoratos G, Halperin JL, Hiratzka LF, Hunt SA, Jacobs AK; American College of Cardiology; American Heart Association Task Force on Practice Guidelines; Canadian Cardiovascular Society: ACC/AHA guidelines for the management of patients with ST-elevation myocardial infarction: a report of the American College of Cardiology/American Heart Association Task Force on Practice Guidelines (Committee to Revise the 1999 Guidelines for the Management of Patients with Acute Myocardial Infarction). Circulation 2004, 110:e82-e292.

4. Van de Werf F, Bax J, Betriu A, Blomstrom-Lundqvist C, Crea F, Falk V, Filippatos G, Fox K, Huber K, Kastrati A, Rosengren A, Steg PG, Tubaro M, Verheugt F, Weidinger F, Weis M; ESC Committee for Practice Guidelines (CPG): Management of acute myocardial infarction in patients presenting with persistent ST-segment elevation. Eur Heart J 2008, 29:2909-2925.

5. Sjauw KD, Engström AE, Vis MM, van der Schaaf RJ, Baan J Jr., Koch KT, de Winter RJ, Piek JJ, Tijssen JG, Henriques JP: A systematic review and metaanalysis of intra-aortic balloon pump therapy in ST-elevation myocardial infarction: should we change the guidelines? Eur Heart J 2009, 30:459-468.

6. Hochman JS, Sleeper LA, Webb JG, Sanborn TA, White HD, Talley JD, Buller CE, Jacobs AK, Slater JN, Col J, McKinlay SM, Le Jemtel TH: Early revascularization in acute myocardial infarction complicated by cardiogenic shock. N Engl J Med 1999, 341:625-634.

\section{doi:10.1186/cc12520}

Cite this article as: Khashan MY, Pinsky MR: Does intra-aortic balloon support for myocardial infarction with cardiogenic shock improve outcome? Critical Care 2013, 17:307. 